\title{
Perspectivas de alunos do PROEJA sobre a utilização do Moodle na aprendizagem de matemática
}

Lisani Geni Wachholz Coan

Floriano Viseu

\begin{abstract}
Resumo
A proliferação do uso dos meios de comunicação eletrônica proporciona formas de complementar as atividades de aprendizagem, principalmente com alunos da Educação de Jovens e Adultos (EJA), como é o caso do PROEJA. Ao atender o retorno de alunos de PROEJA à escola, integrou-se a Plataforma Moodle na regulação das suas aprendizagens na disciplina de Matemática. Com base nas atividades desenvolvidas na sala de aula e no ambiente virtual de aprendizagem, procurou-se averiguar as perspectivas dos alunos sobre o contributo da utilização do Moodle na sua aprendizagem de conteúdos matemáticos. A investigação foi orientada por uma abordagem qualitativa e interpretativa, seguindo o design de estudo de caso. O uso dessa ferramenta proporcionou aos alunos uma aprendizagem mais dinâmica e envolvente, possibilitando-lhes o acesso ao conhecimento por outros meios, de modo que o conteúdo escolar de matemática passou a ter novo sentido para eles. Oportunizou-lhes tirar suas dúvidas com seus colegas e professores por e-mail ou mensagens nos fóruns temáticos.
\end{abstract}

Palavras-chave: Aprendizagem de matemática; Alunos do PROEJA; Plataforma Moodle.

\section{Abstract}

The growing use of electronics provides ways of reinforcing learning activities, especially with EJA students (Educação de Jovens e Adultos) in the PROEJA program. In our care of PROEJA students returning to school, we integrate the Moodle platform as a basis for their learning in the subject of mathematics. Based on the activities developed in the classroom and the virtual learning environment, we seek to discover students' perspectives in the use of Moodle for their learning of mathematic skills. The study was led by an approach both qualitative and interpretive, following the design of the case study. The use of this tool provided them a more dynamic and engaging learning experience as it made it possible for the students to access knowledge by other means and thus could perceive that the mathematic content had a new meaning to them. It provided them the opportunity to clear their doubts with their fellow students and teachers by email or theme forum discussions.

Keywords: Learning mathematics; PROEJA Students; Moodle platform. 


\section{Introdução}

Na sociedade contemporânea, as Tecnologias de Informação e Comunicação (TIC) estão cada vez mais presentes na atividade humana, desafiando a escola a integrá-las nas ações que se desenvolvem no contexto educacional. Considera-se que as TICS auxiliam consideravelmente o processo de ensino e aprendizagem se forem integradas e utilizadas adequadamente (MIRANDA, 2007; PONTE e CANAVARRO, 1997).

O presente artigo aborda o uso da Plataforma Moodle nas atividades de aprendizagem de Matemática em turmas de PROEJA do IFSC. Destaca-se que o uso do computador ainda é uma novidade para muitos alunos dessa modalidade de ensino, especialmente quando essa ferramenta é integrada nas estratégias de ensino de Matemática, que, segundo eles, é o professor o responsável por lhes fazer chegar a informação dos conteúdos desta disciplina. Para esses alunos, as possibilidades de acesso ao uso de tecnologias são alargadas em consequência do reinício de uma nova etapa nas suas vidas por meio do retorno aos estudos. Assim, analisam-se as perspectivas dos alunos sobre a utilização dessa ferramenta tecnológica como um meio de acessar a informação matemática, para além da que lhes é transmitida pelo professor, e poderem assim aprofundar o que aprenderam na sala de aula. Nesse aprofundamento, o uso da Plataforma Moodle proporcionou-Ihes uma aprendizagem mais significativa, especialmente por que eles tiveram, além do professor, outros meios de otimizar o acesso à informação matemática tratada na sala de aula. Segundo Ausubel $(1960,2003)$, a aprendizagem pode ser incorporada à estrutura cognitiva tanto de forma significativa como de forma mecânica. A aprendizagem torna-se significativa quando o aluno dá sentido ao que aprende, ou seja, a informação interage e se ancora nos conceitos relevantes já existentes na sua estrutura cognitiva. Para que uma aprendizagem seja significativa consideram-se duas características: (i) o aluno precisa ter disposição para aprender; e (ii) o conteúdo escolar deve necessariamente ser significativo para o aluno. Mediante o uso do Moodle, os alunos da Educação de Jovens e Adultos foram instigados a perceber que a Matemática não se resume a um conjunto de formalismos sem sentido e de difícil compreensão, mas que se trata de uma disciplina cujos conhecimentos resultam da atividade humana, o que a torna uma disciplina viva e em desenvolvimento (DAVIS \& HERSH, 1995).

A temática pautada em torno do acesso e do uso das TIC instiga-nos para uma reflexão sobre o papel da Escola na sociedade contemporânea. Percebe-se que o intenso uso das tecnologias remete para uma nova leitura sobre a dinâmica de sua integração no contexto educativo.

\section{As TIC para além da sociedade da informação}

Atualmente, os tempos resguardam determinados desafios que perpetuam as sociedades contemporâneas nas suas mais variadas dimensões e perspectivas. Um desses desafios refere-se à 
efetiva compreensão por parte dos cidadãos do que vem a ser o consumo de informação. Diariamente, somos confrontados com novas expressões que são tacitamente aceitas porque soam como uma promessa de algo inovador e de solução aos problemas que assolam os indivíduos (BIANCHETTI, 2001). Dentre algumas dessas expressões que caracterizam os tempos marcantes da evolução tecnológica e civilizacional situam-se as seguintes: Sociedade da Informação (SI), Sociedade do Conhecimento, Tecnologias de Informação (TI), Tecnologias de Informação e Comunicação (TIC), Novas Tecnologias de Informação e Comunicação (NTIC), Revolução Tecnológica. Segundo Bianchetti (2001), tais expressões não precisam necessariamente ser compreendidas, uma vez que elas passam a ser aceitas e rapidamente integram o vocabulário das pessoas "independentemente das suas características e posições culturais, sociais, profissionais e ideológicos" (BIANCHETTI, 2001, p. 52). Tal fato se deve ao uso de artifícios de linguagem e também por se apostar na elaboração de imagens que interferem no processo de construção de tais expressões.

Para Miranda (2007), é fundamental que se perceba o seu contexto para que se tenha a devida clarificação conceitual. Por exemplo, o uso das expressões Sociedade da Informação e Sociedade do Conhecimento, por vezes, tem sido apresentado como sendo sinônimas. Ponte e Canavarro (1997) observam que, inicialmente, havia pouca distinção entre os dois conceitos e enfatizam que a generalização das novas tecnologias não garante que possuir muita informação implique saber utilizá-la. No entanto, esses autores lembram que a essência do conhecimento situa-se na capacidade da utilização de diferentes recursos que permitam obter a informação quando ela se torna necessária.

Estudos de Masson e Mainardes (2011) indicam que acessar a informação não representa uma democratização do conhecimento, pois o acúmulo quantitativo de informação não garante a devida apropriação do conhecimento. Para esses autores, "a transformação de informações em conhecimento requer um conjunto de habilidades que promovam um trabalho interno de reflexão que organize as informações desconexas num corpo coerente de pensamento" (MASSON e MAINARDES, 2011, p. 80). Assim, pensar uma Sociedade da Informação e do Conhecimento sugere que se leve em consideração que as TIC são tecnologias com perspectivas sociais e cognitivas, o que favorece e instiga que elas sejam verdadeiramente integradas e otimizadas de forma eficaz no sistema educativo (PONTE, 2000). A revolução tecnológica tem impulsionado distintas formas de interação entre os indivíduos que, por sua vez, proporcionam novos debates na educação, especialmente no processo de ensino e aprendizagem bem como na formação dos docentes.

Mediante tais considerações, perspectiva-se tirar pleno partido do grande potencial que as tecnologias apresentam e torna-se necessário efetuar sua otimização no sistema educativo de modo que o seu uso auxilie na produção do conhecimento para além do acesso à informação. Desse modo, a integração das TIC no processo de ensino-aprendizagem, como, por exemplo, o 
uso de ambientes virtuais de aprendizagem, nos convida para uma discussão que perpassa a aquisição e desenvolvimento de capacidades sobre a autonomia do aluno referentes ao seu aprender e pensar (DIAS, 2004). Para esse autor, trata-se de novas formas de comunicar e acessar à informação. Tal dinâmica requer do professor a devida clareza do que representa o uso das TIC no seu espaço profissional para que a sua utilização seja um recurso positivo ao processo de ensino e torne a aprendizagem mais cativante, dinâmica e eficaz.

O expressivo desenvolvimento das TIC e o impacto que a sua utilização tem na sociedade atual contribuíram para que o espaço escolar sofresse algumas modificações, embora de uma forma desigual, uma vez que vários fatores influenciam as prioridades e as demandas de políticas em cada país. Nas últimas décadas, estudiosos e pesquisadores se debruçaram diante de várias iniciativas realizadas no sistema educativo numa tentativa de perceber qual é a melhor forma de usar e integrar as novas tecnologias nesse contexto. Registra-se uma relativa inquietação por parte dos pesquisadores e representantes do sistema educativo de modo que seja otimizada a efetiva utilização das TIC nesse espaço, não mais do uso pelo uso mas sim sobre o pleno partido que se deve tirar dessas tecnologias. Alguns estudos têm sinalizado que a simples presença das tecnologias no sistema educativo não faz, por si só, a devida diferença (BONILLA, 2005; KENSKI, 2008; MIRANDA, 2007; PONTE e CANAVARRO, 1997). Para Miranda (2007), não se pode esperar bons resultados na aprendizagem dos alunos se "acrescentar a tecnologia às atividades já existentes na escola e nas salas de aula, sem nada alterar nas práticas habituais de ensinar" (MIRANDA, 2007, p. 44). Ainda de acordo com a autora, a falta de proficiência que muitos professores manifestam no uso das tecnologias, principalmente as computacionais, decorre da falta de recursos e de formação. Miranda (2007) enfatiza que, por parte dos professores, deve haver uma prédisposição para que as suas concepções e práticas de ensino sejam inovadas com a integração das tecnologias. Por outro lado, não basta somente o professor perceber que deve inovar e que é possível tornar o processo de aprendizagem mais dinâmico e mais significativo para os seus alunos se no seu ambiente de trabalho o acesso às tecnologias ainda é algo distante.

Borba e Penteado (2007) destacam que no Brasil ainda há muitas escolas que nem sequer possuem Laboratórios de Informática e, quando têm e funcionam, o seu acesso torna-se um obstáculo porque o professor responde como sendo o único responsável pelo uso de todos os equipamentos. Observa-se que os professores que apostam e integram os recursos tecnológicos na sua dinâmica de trabalho nem sempre tem a seu favor a devida infraestrutura que viabilize a utilização das mesmas. Isso requer uma iniciativa por parte dos professores que percebem o potencial do uso das TIC na prática pedagógica. A exemplo disso, no Instituto Federal de Santa Catarina (IFSC), desde 2007, os professores do ensino presencial têm-se familiarizado mais intensamente com ambientes virtuais de aprendizagem, particularmente com a utilização da Plataforma Moodle, por oferecerem uma alternativa de comunicação entre alunos e professores. Os professores se capacitaram por meio de cursos de formação continuada sobre a integração das 
TIC no processo de ensino com o advento da implementação e oferta da Educação a Distância (EaD). Inicialmente, os cursos eram direcionados para os professores que tinham vínculo com a oferta da EaD. À medida que foram sendo ofertados cursos de capacitação para os demais professores, percebeu-se que o uso do Moodle se tornou uma ferramenta aliada ao processo de ensino. Isso possibilitou a integração dessa ferramenta no desenvolvimento das atividades de aprendizagem da Matemática na modalidade de Educação de Jovens e Adultos (EJA), para os alunos de alguns cursos do Programa Nacional de Integração da Educação Profissional com a Educação Básica, na Modalidade de Educação de Jovens e Adultos (PROEJA) do IFSC. Com intuito de perceber como os alunos do ensino presencial, no caso alunos de turmas do PROEJA, integram a Plataforma Moodle nas suas atividades de aprendizagem, procurou-se averiguar as suas perspectivas sobre a utilização desta plataforma no seu desempenho escolar.

\section{O dispositivo do processo de ensino e aprendizagem de matemática}

Dentre diversas possibilidades que as TIC proporcionam no processo de ensino e aprendizagem, destaca-se o uso do computador ligado à Internet (MIRANDA, 2007). Para essa autora, os professores devem saber tirar partido do 'arsenal' tecnológico que têm à sua disposição com os alunos na exploração, tratamento e representação da informação de modo que o seu uso corrobore na construção de conhecimentos que auxiliem o desenvolvimento de projetos, entre outros fatores. Os resultados positivos estão relacionados com a forma como é usado o computador em razão de atender o lado mais construtivo e criativo que tais ferramentas dispõem. Independentemente qual seja a idade do aluno ou qual seja a área de atuação de um professor, parte-se do pressuposto que o uso das TIC não pode ser uma mera reprodução de antigas práticas pedagógicas. Atentos a tais pressupostos, esboçou-se um dispositivo que regulasse o processo de ensino e de aprendizagem na unidade curricular de Matemática para alunos da modalidade de Educação de Jovens e Adultos do Instituto Federal de Santa Catarina (IFSC), através da complementaridade entre a sala de aula e a Plataforma Moodle. Procurou-se com esses ambientes de aprendizagem instigar, entre outros, a troca de ideias, a entreajuda, a clarificação das dificuldades e a partilha de experiências. Tais espaços e formas de interlocução não seguiram necessariamente uma sequência cronológica de acontecimentos, pois um item de discussão tanto podia ser inicializado no ambiente virtual e ter continuidade em sala de aula ou vice-versa (Figura 1). 


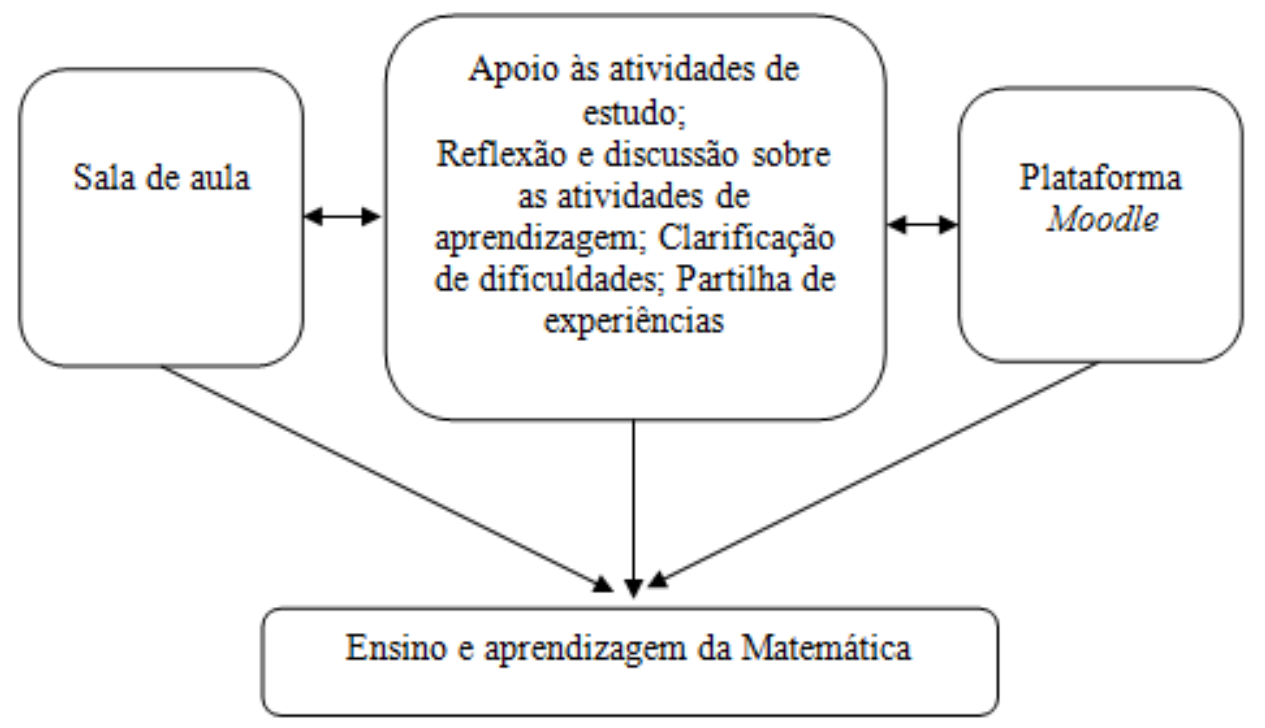

Figura 1- Itens do dispositivo do processo de ensino e aprendizagem

(Fonte: COAN, 2012, p.147).

Essa dinâmica promoveu diferentes formas de comunicação entre os alunos e entre os alunos e o professor de modo a lhes proporcionar a possibilidade de refletir sobre as atividades por eles desenvolvidas, tanto em sala de aula como no ambiente virtual. Estimulou-se a entreajuda e a clarificação de dificuldades de aprendizagem através de momentos de discussão sobre as atividades desenvolvidas.

Os professores organizaram e disponibilizaram diversas tarefas no ambiente virtual de modo que os alunos as efetuassem em grupo ou individualmente. No caso das três turmas que fizeram parte do estudo, foram colocadas diferentes atividades de aprendizagem na Plataforma Moodle, que instigou nos alunos a um maior envolvimento nas tarefas propostas. As atividades tiveram, por vezes, o seu início na sala de aula e, outras vezes, no ambiente virtual de aprendizagem. Foi-lhes proporcionado um reforço sobre o que haviam aprendido em sala de aula, um espaço para tirarem as suas dúvidas, realizarem diversas tarefas individuais, em díades ou em grupo, tirarem partido do fórum e do e-mail para interagirem com colegas e com o seu professor.

Os alunos que participaram no Moodle puderam explorar a representação gráfica no estudo de funções por meio de vídeos, de softwares como o GeoGebra e o applet do Descartes, o que thes proporcionou uma dimensão mais ampla dos conteúdos que estavam estudando. Os alunos realizaram pesquisas sobre alguns temas propostos, resolveram e postaram exercícios no ambiente virtual de aprendizagem, alguns fizeram prova de recuperação e tiveram no espaço do fórum a oportunidade de trazerem as suas contribuições e de interagirem com os colegas e professor. Também fizeram uso do e-mail para estabelecerem diálogos com os colegas e seu professor que estavam diretamente envolvidos no processo de ensino-aprendizagem. Alguns 
participantes deste estudo, dado o contexto e a limitação de acesso ao computador com Internet, fizeram mais do que dois acessos ao ambiente virtual por semana, mas a sua participação no fórum ficou aquém do esperado.

\section{Aspectos metodológicos}

A presente investigação seguiu uma abordagem qualitativa e interpretativa por transcorrer num ambiente natural no qual se pretendeu observar e descrever as ações vivenciadas pelos participantes, sem retirar o significado por eles atribuído (BOGDAN e BIKLEN, 1994; ERICKSON ,1986;) FLICK, 2009). O método de pesquisa em questão permitiu a utilização de diferentes instrumentos de coleta de dados, tais como a observação, entrevista, questionário (Inicial e Final) e análise documental. Segundo Bogdan e Biklen (1994) e Yin (2005), essa variedade de métodos possibilita que a triangulação de dados represente uma alternativa à validação dos mesmos.

Procurou- se investigar a forma como os alunos de PROEJA utilizaram a Plataforma Moodle no desenvolvimento das suas tarefas propostas pelo professor de Matemática, a pertinência da complementaridade entre a sala de aula e o ambiente virtual e as suas perspectivas sobre o uso dessa plataforma na aprendizagem de conteúdos matemáticos. Para concretizar o objetivo que orientou esta investigação, procuramos responder a seguinte questão: Que perspectivas têm os alunos do PROEJA sobre a utilização da Plataforma Moodle na aprendizagem de Matemática?

Os participantes deste estudo foram os alunos de três turmas distintas de cursos do PROEJA do IFSC, denominadas, respectivamente, por Turma A (turma de PROEJA do Curso Técnico de Enfermagem, Câmpus de Florianópolis), Turma B (turma de PROEJA do Curso Auxiliar de Cozinha, Câmpus do Continente) e Turma C (turma de PROEJA do Curso Técnico de Eletromecânica, Câmpus de Chapecó). As três turmas eram constituídas por 19, 8 e 19 alunos, respectivamente. Os três professores são identificados como Professor A (Turma A), Professor B (Turma B) e Professor $C$ (Turma $C$ ). Esse processo se estendeu ao longo de um semestre letivo.

Em cada uma das três turmas foram selecionados quatro alunos atendendo a fatores que envolveram sua participação na Plataforma Moodle (maior participação, razoável participação e pouca participação). Adotando essa metodologia, estruturaram-se três estudos de caso, sendo cada um deles constituído por quatro alunos das três turmas do IFSC: da Turma A (Helena, Daniela, Paula e Sabrina); da Turma B (Pedro, Letícia, João e Cristine) e da Turma C (Eric, Silva, Cristiano e Anderson). No presente estudo, as unidades de análise, que deram origem aos respectivos casos, atenderam aos critérios de maior participação (Helena, Daniela, Pedro e Eric); razoável participação (Paula; Letícia, João e Silva); e pouca participação (Sabrina, Cristine, Cristiano e Anderson) no ambiente virtual de aprendizagem. Levando-se em consideração as diferentes atividades que os alunos desenvolveram nesse ambiente, tomou-se como referência: (i) a sua participação no fórum; (ii) o envio de mensagens de e-mail; (iii) o número de vezes que 
ele fez o acesso, bem como a forma que tirou partido de todos os seus acessos, os quais são caracterizados pelo número de registros que cada usuário tem na Plataforma Moodle, conforme sugere a Tabela 1.

Tabela 1 - Frequência da participação dos alunos dos estudos de caso no Moodle.

\begin{tabular}{|c|c|c|c|c|c|}
\hline Turmas & Alunos & Fórum & e-mails & № acessos & № registos \\
\hline \multirow{4}{*}{ Turma A } & Helena & 35 & 26 & 64 & 1009 \\
\hline & Daniela & 28 & 14 & 46 & 639 \\
\hline & Paula & 16 & 12 & 16 & 217 \\
\hline & Sabrina & 6 & 6 & 10 & 159 \\
\hline \multirow{4}{*}{ Turma B } & Pedro & 25 & 26 & 38 & 568 \\
\hline & Letícia & 21 & 15 & 27 & 397 \\
\hline & João & 18 & 10 & 22 & 265 \\
\hline & Cristine & 7 & 5 & 11 & 203 \\
\hline \multirow{4}{*}{ Turma C } & Eric & 27 & 22 & 35 & 826 \\
\hline & Silva & 19 & 13 & 18 & 325 \\
\hline & Cristiano & 9 & 6 & 10 & 105 \\
\hline & Anderson & 8 & 4 & 8 & 98 \\
\hline \multicolumn{2}{|r|}{ Total } & 219 & 159 & 305 & 4811 \\
\hline
\end{tabular}

Destaca-se que os valores apresentados, respectivamente, nas três turmas não podem ser comparativos, pois há uma discrepância entre número de alunos de turma a turma, bem como o efetivo número de semanas de uso do ambiente virtual. A tabela anterior apresenta o número de registros dos alunos na Plataforma Moodle, que para Pulino Filho (2005) representa o cômputo que a ferramenta Registros faz uma vez que ela permite visualizar todas as atividades dos participantes do curso. Mediante os dados apresentados na tabela, os alunos, Helena, Daniela, Pedro e Eric atendem o fator 'maior participação na Plataforma Moodle'. Os alunos, Paula; Letícia, João e Silva participaram razoavelmente; e Sabrina, Cristine, Cristiano e Anderson, foram os alunos considerados com pouca participação nesse meio.

A coleta dos dados envolveu a realização de entrevistas com os doze alunos das respectivas turmas, apresentados na Tabela 1, além das informações geradas pelo uso do ambiente virtual 
pelos alunos. O estudo de caso recorre a diferentes técnicas próprias da investigação qualitativa. O presente estudo integrou múltiplas fontes de evidência ou de dados, que, segundo Yin (2005), evidenciam os diferentes olhares sobre um mesmo fenômeno e também asseguram distintas perspectivas dos indivíduos que integram a investigação, proporcionando as devidas condições para efetuar a triangulação dos dados na sua fase de análise.

A codificação das fontes de informação utilizadas na recolha de dados varia de acordo com os instrumentos utilizados para os mesmos: Questionário Inicial (Aluno $n, Q 1, n \in\{1,2, \ldots 19\}$ ); Questionário Final (Aluno $n, Q 2, n \in\{1,2, \ldots 19\}$ ) e Entrevista a alunos (EA, realizada com os doze alunos das unidades de análise). Observa-se que o questionário foi aplicado a todos os alunos das três turmas, para que inicialmente se tivesse um desenho mais detalhado relativo às expectativas dos alunos sobre o uso de computador numa disciplina que, até então, não tinha essa prática, bem como para saber se os alunos tinham hábitos de usar computador ou não. No final dos estudos fez-se nova consulta com todos os alunos de modo a perceber o que thes representou a integração das TIC no processo de ensino e aprendizagem de conhecimentos matemáticos.

Antes de apresentar os dados sobre o uso da Plataforma Moodle pelos alunos de cursos do PROEJA, busca-se abordar algumas peculiaridades sobre a trajetória de vida desses alunos. Tais aspectos auxiliam a compreensão sobre questões pertinentes ao uso das TIC de um modo geral e enriquecem as informações advindas de cidadãos que abrem mão dos estudos por diversos motivos.

\section{Retornar aos estudos: a realização de um sonho}

Histórias emocionantes permeiam a trajetória de vida dos alunos da Educação de Jovens e Adultos, especialmente por que não é tarefa fácil conciliarem o retorno à escola depois de tantos anos fora dela. Uma das características dos alunos de cursos do PROEJA é a descontinuidade, por diversas razões, no processo escolar. Geralmente tiveram que 'abrir mão' dos estudos para dar conta de seus filhos pequenos, ou para, enquanto crianças, trabalhar para auxiliar no rendimento familiar ou porque moravam muito longe de uma escola. A possibilidade do retorno à escola para alunos que têm histórico de descontinuidade escolar geralmente se dá por meio da modalidade de Educação de Jovens e Adultos. Desde 2005, o governo brasileiro faz tentativas no sentido de atender a população de trabalhadores na rede federal de ensino por meio da oferta de vagas em cursos técnicos para os alunos que não tiveram oportunidade de dar continuidade em seus estudos na idade considerada "ideal". Em 2006, foi implementada a segunda versão do Programa Nacional de Integração da Educação Profissional com a Educação Básica na Modalidade de Educação de Jovens e Adultos (PROEJA), pelo Decreto de no 5.840, de 13 de julho de 2006, obrigando os Institutos Federais a destinarem dez por cento de suas vagas oferecidas anualmente para o público da EJA. O objetivo do PROEJA é proporcionar "a elevação do nível de escolaridade 
do trabalhador" (BRASIL, 2006), levando-se em consideração as características dos jovens e adultos, uma vez que possibilita articular a Educação Profissional ao Ensino Fundamental ou ao Ensino Médio. Ou seja, objetiva atender à demanda de cidadãos jovens e adultos por meio da oferta de educação básica e profissional propiciando-lhes a elevação de escolaridade, profissionalização, continuidade de estudos e maior inserção na vida social e no mundo do trabalho.

Os principais fatores que motivaram os alunos ao retorno de seus estudos são a necessidade de uma qualificação profissional, a aquisição de conhecimento e o desejo de ter uma profissão. A falta de escolaridade é responsável pela grande rotatividade nas vagas de empregos. Destaca-se que somente quatro alunos da Turma A estão há mais de cinco anos na mesma profissão, estando os demais ou desempregados ou inseridos num serviço novo. Os depoimentos dos alunos apresentam traços comuns sobre o que representa regressar à escola uma vez que representa a realização de um sonho adormecido ou quase impossível de acontecer. Por exemplo, Helena (Turma A) é uma aluna com uma história de vida marcante. Entre os treze e os catorze anos saiu de casa, motivo pelo qual largou bem cedo os seus estudos, com "a roupa do corpo e pegar a estrada (...) deixei a mãe e o pai porque eu vim de uma criação muito severa, apanhei muito em colégio de freira. Um dos traumas meus!" (HELENA, EA). Hoje, voltar aos estudos aos cinquenta e poucos anos a fez relembrar como a escola e a família daquela época se orientavam por regras rígidas que, por sua vez, também se repercutiam nas aulas de Matemática. Tristemente resguarda as lembranças da cicatriz que tem na testa, marca que interferiu fortemente na aprendizagem de Matemática e de Português para Helena, porque "eram as duas matérias que eu apanhei muito" (EA). A referência que Helena faz ao verbo apanhar não é no sentido de sentir dificuldades de aprendizagem, mas sim de sofrer tortura mesmo.

Assim como a Helena expressa o sentimento sobre sua trajetória escolar na infância e adolescência, para Pedro (Turma B) é o retorno para a escola que o encantou, pois realizou o sonho de concluir o Ensino Médio, meta nunca antes alcançada. Esse aluno conseguiu voltar aos estudos aos 54 anos de idade e trabalha como eletricista há oito anos. Voltar a estudar sempre foi o seu objetivo e depois de concluir o Curso Técnico Auxiliar de Cozinha passou para outro Curso Subsequente no Campus Florianópolis. Contudo, Pedro reconhece que o ambiente escolar que conheceu no IFSC não se iguala às lembranças dos traumas de uma aprendizagem rude que obrigava as crianças a ajoelharem-se em cima de tampas de garrafa ou de grãos de milho. Segundo Pedro, tais atitudes eram um hábito comum e utilizado pelos professores para educar as crianças daquela época. Essas práticas "cortavam os joelhos das crianças, machucava as crianças. (...) Agora, está sendo muito bom! Eu aprendo com facilidade, eu só quero aprender! Acompanho bem o ritmo dos estudos" (PEDRO, EA).

Daniela (Turma A) retornou aos estudos aos 32 anos, depois de 13 anos de afastamento devido ao nascimento da sua filha. Ela consegue conciliar emprego e estudos para ter um futuro 
melhor. Durante esses anos chegou a matricular-se algumas vezes, mas como não tinha com quem deixar a sua menina não pôde concretizar a sua meta mais cedo. Cansada de trabalhar por longos anos consecutivos de empregada doméstica, sabe que para conseguir algum emprego noutra área precisa concluir os seus estudos. Foi assim que decidiu se inscrever no IFSC para fazer o curso de Enfermagem.

Os outros cinco alunos deste estudo evidenciam particularidades semelhantes na sua trajetória escolar em idade regular. Na ocasião, todas as forças convergiam para manter essas crianças fora da escola. Sabrina (Turma A) deixou seus estudos quando criança porque desde os 9 anos teve que cuidar da casa e de seus irmãos, pois sua mãe trabalhava o dia inteiro. A falta de tempo para estudar teve consequências na sua progressão escolar, pois Sabrina faltava muito e acabava reprovada por vários anos consecutivos. Voltar aos estudos quando adulta foi a meta que perseguiu, pois se sentia envergonhada perante seus filhos por não ter ainda concluído o Ensino Médio.

Destaca-se que para todos os alunos que constituem o estudo de caso, o IFSC representou uma porta aberta em suas vidas. Além de conseguirem a certificação do Ensino Médio, tiveram a certificação profissional. Para os que desejaram continuar os estudos, a oportunidade de progressão em outros cursos também virou realidade, como foi o caso de Letícia (Turma B). Mesmo sendo aluna com formação em curso do PROEJA, Letícia concorreu com vários alunos do Ensino Médio regular no exame de classificação para ingresso em 2012, numa disputa com mais de dez candidatos por vaga. A sua persistência e vontade de promover mudanças de atitudes certamente acompanharam Letícia na disputa por uma vaga no Curso Segurança do Trabalho. Letícia mal concluiu um curso e já conseguiu ingressar noutro.

Os alunos da Turma $\mathrm{C}$ diferem das demais em relação à idade dos alunos. De 19 alunos, oito estão com menos de 23 anos, seis estão entre 24 e 29 anos, quatro se situam entre 30 e 39 anos e um deles tem mais de cinquenta anos. Os alunos mais jovens dessa turma começaram a trabalhar bem cedo e mantêm-se no mesmo emprego por um período maior. Por exemplo, o aluno de 22 anos de idade está há cinco anos no mesmo emprego; outro aluno de 19 anos exerce há três anos a sua profissão de auxiliar de mecânico. Apenas dois alunos de 19 anos estão no primeiro ano em seu emprego, os demais estão por vários anos consecutivos desempenhando a mesma função. Os empregos por eles citados são de operador de máquinas (3), mecânico industrial ou torneiro mecânico (8), pedreiro (1), laminador (1), eletricista (1), supervisor ou auxiliar de produção (2), representante de vendas (1), funcionário público (1) e dono de pequena empresa (1).

Vários alunos da Turma C residem longe do IFSC, o que na sua infância foi um fator de impedimento na continuidade dos estudos. Quatro dos 19 alunos estiveram mais de dez anos sem estudar por morarem no interior bem como pela falta de incentivos de seus pais e a falta de transporte, tal como refere um aluno: "o trabalho e o pouco incentivo dos pais fiquei longe dos 
estudos" (Q1). Para esse aluno, as razões que o fizeram retornar para a escola foi a busca de "conhecimentos, os que eu tinha para o cargo que eu exerço estavam atrasados" (Q1).

No caso do aluno Eric (Turma C), um jovem de dezenove anos, com uma personalidade tímida, começou a trabalhar aos doze anos num posto de lavagem, estudava de manhã e trabalhava no período vespertino. Teve a sua adolescência dividida entre os estudos e o trabalho. Aos quinze anos, começou a trabalhar o dia todo e estudava de noite. Um ano depois, teve o seu primeiro emprego com carteira registrada, exercendo a função de Auxiliar de Mecânica de Motos. Passou para Auxiliar de Mecânica Industrial e atualmente exerce a função de Auxiliar de Mecânico noutra empresa. Os seus pais sempre o incentivaram estudar. Também Cristiano (Turma C), de 23 anos, interrompeu os seus estudos porque os horários com seu trabalho não eram compatíveis. Quando deixou a escola, esse aluno cursava o primeiro ano do Ensino Médio. Ele ficou cinco anos fora do contexto escolar até a oportunidade que teve de ingressar no IFSC. Cristiano é filho de mãe que não teve oportunidade de estudar, por isso ele reconhece o quanto é importante aproveitar as chances que a vida proporciona.

As histórias desses alunos confirmam que o PROEJA cumpre o seu papel. O mais importante de tudo isso não é somente oportunizar o seu reingresso numa escola, mas sim fazer com que os alunos percebam que a partir desse momento o estudo tornou-se um diferencial em suas vidas. Nessa perspectiva, eles têm motivação para concluírem seus estudos, o que nem sempre é algo tão simples na vida do trabalhador, conciliar trabalho e estudo. A garantia da qualidade da educação é mediada pelas condições que encontram no ambiente escolar, o qual precisa oferecer-lhes as devidas possibilidades de prosseguirem em níveis de escolarização mais avançados. Essa qualidade está diretamente ligada ao grupo de professores que trabalham nesses cursos e do entendimento do que representa trabalhar com um público de alunos da EJA. Os professores que trabalham com alunos de turmas de PROEJA extrapolam paradigmas consensuais do processo de ensino e aprendizagem porque estabelecem entre eles uma sintonia diferenciada por conta das histórias marcantes que cada um dos alunos traz e vivencia. Os professores de Matemática das três turmas, além de se identificarem com a modalidade da EJA, aceitaram positivamente a proposta da aplicação do dispositivo de ensino e aprendizagem de matemática para alunos de cursos do PROEJA do IFSC.

\section{Perspectivas dos alunos sobre a utilização do Moodle}

Os ambientes virtuais de aprendizagem proporcionam diferentes formas de comunicação, que serve de elo de interação entre os próprios alunos e também entre estes e o seu professor. Na Plataforma Moodle deu-se início à discussão de determinados assuntos para as aulas posteriores, uma vez que ali foram postadas tarefas com o objetivo de realizá-las em futuros momentos da sala de aula. Essas tarefas envolviam o conteúdo apresentado por meio de vídeos, 
textos, links entre outros, os quais relacionaram diferentes temas mencionados ao contexto da Matemática ora em estudo. Os conteúdos da disciplina de Matemática que foram estudados perpassam os tópicos de: 1- Estudo de Função; 2- Função do Primeiro e Segundo Graus; 3Teorema de Pitágoras; 4- Trigonometria do triângulo retângulo (razões trigonométricas); 5- Lei dos senos e Lei dos cossenos.

Ao longo do semestre, os alunos das três turmas desenvolveram diferentes atividades. Desse modo, buscou-se saber o que representou para eles a experiência de usar computador nas atividades de aprendizagem de Matemática. Ao distinguirem as atividades que realizaram na sala de aula das que realizaram no Moodle, os alunos puderam expressar as diferenças percebidas pela integração dessa ferramenta nas atividades de aprendizagem. Ressalta-se que os doze alunos que constituem as unidades de análise do presente estudo destacam que a integração das TIC no processo de ensino foi positiva. Para Helena (Turma A), a experiência foi significativa porque ela era uma aluna que costumava estudar de madrugada, no silêncio. Conhecer essa ferramenta possibilitou "rever as coisas que já foram vistas, no momento que é melhor para mim" (EA). Helena, sempre muito atenta a todas as questões que surgiam na turma, observa que essa curiosidade contagiou as suas colegas. Segundo seu depoimento, ter para além da sala de aula a possibilidade de rever e acessar os conhecimentos tratados, proporcionou-lhe um sentimento de autoconfiança com relação à Matemática, especialmente porque essa era a disciplina que ela mais desprezava até então.

"Não tem noção! Era como se fosse um desafio! Ah, eu botei tal coisa! Todo mundo queria ver o que o outro botou. Ah, como que mata aquela charada? (...) Eu acho que é válido porque, por exemplo, como eu tinha os meus momentos de paz e sossego que eu entrava, eu acho que desde o começo a gente tivesse essa ferramenta, o aluno só vai ganhar! Eu vejo a diferença, a vontade que eu tinha de entrar, é diferente de vir na sala de aula de Matemática" (HELENA, EA).

A aluna Daniela (Turma A) destaca que inicialmente ficou assustada quando seu professor anunciou que seria criada uma turma virtual e que estudariam a Matemática por meio do computador. À medida que se foi familiarizando com a ferramenta e fez uso para enviar mensagens via fórum e responder as atividades solicitadas, percebeu as vantagens que essa dinâmica trouxe, principalmente para ela que sabia usar muito pouco o computador: "o proveito que eu tirei também foi aprender a mexer um pouco e entender mais do computador em si, e também sobre o Moodle, como as vantagens e poder entrar em contato com o professor, com outros colegas, tirar dúvida" (DANIELA, EA).

A proposta de integração das TIC no ensino e aprendizagem de Matemática não trouxe prejuízo para os alunos, pelo contrário, os ganhos foram visíveis, conforme reforça a aluna Paula (Turma A): 
"Positivo é poder fora da sala de aula estar revisando, estudando, tudo que aprendeu em sala de aula e de negativo para mim não teve. (...) Prejudicar, não prejudicou, mas pelo fato de muitas alunas não terem acesso ou por não saberem mexer muito bem com o computador algumas não gostaram muito" (PAULA, EA).

A integração e uso das TIC ainda merecem muita atenção, não somente relativo ao sistema educacional, mas de um modo geral de toda a população que contém um grande contingente de pessoas que não sabem sequer ligar um computador. Tal questão pode ser visivelmente observada nesta investigação, uma vez que saber minimamente usar um computador foi um obstáculo para vários alunos. Esse aspecto ficou evidenciado nas três turmas e foi um limitador para alcançar a totalidade dos alunos envolvidos e intensificar uma maior participação deles na Plataforma Moodle. Por exemplo, a primeira reação de Sabrina foi de espanto: "Eu logo pensei, meu Deus! Como a Matemática no computador? Como eles vão fazer isso?" (EA). Eric (Turma C) confessa que a proposta foi impactante para ele e seus colegas, pois "a gente ficou meio assustado assim na verdade porque a gente nunca tinha feito isso antes" (EA).

Para Letícia (Turma B), demorou até se convencer que ao participar na sala virtual o acesso era restrito aos seus colegas da sala presencial. Tanto é que ela não tinha coragem de escrever nos fóruns pela falta de confiança de se expor. Contudo, acessava com frequência e resolvia as tarefas propostas pelo professor. No final do semestre ela foi enfática ao destacar a diferença que sentiu por ter a oportunidade de estudar com esse recurso. Para essa aluna, "a gente não depende só daquela única aula de Matemática durante a semana, de quadro e giz" (EA), além de que essa ferramenta a colocou diante de desafios que a fez entender o significado de seus erros em resolução de exercícios. Ela destaca que o uso do Moodle the proporcionou superar suas dificuldades especialmente porque lhe oportunizou rever o que havia visto em sala de aula: “Aquelas dificuldades que eu tinha (...), os exercícios que eu levava no caderno e não conseguia, e no Moodle eu ia em busca, (...) eu queria saber o porquê que estava errado" (LETíCIA, EA).

O aluno Pedro (Turma B) lembra que inicialmente não tinha hábito de usar computador e considera que foi positivo ter tido a oportunidade de conhecer a Matemática por outros meios. Pedro destaca que o uso da Plataforma Moodle favoreceu sua aprendizagem "apenas eu não estava assim acostumado com aquele método que ia somar com o aprendizado da Matemática. Não estava acostumado. Nunca tinha visto isso aí! Mas foi bom!" (Pedro, EA). Para seu colega João, o uso do Moodle favoreceu sua aprendizagem matemática porque assim lhe foi oportunizado o acesso aos conhecimentos tratados em sala de aula. João precisava conciliar dois empregos e seus estudos, por isso nem sempre podia estar presente em todas as aulas. Diante dessa situação, João reconhece que o uso das TIC foi "uma forma de aprender mais! (...) A turma ficou mais unida com o uso dessa ferramenta" (EA). 
Dentre as diversas atividades desenvolvidas nas turmas A e B, os alunos fizeram uso de applets do Geogebra, o qual Ihes oportunizou averiguar possíveis erros em resoluções de exercícios, especialmente nos conhecimentos de funções do 1.ํ e 2. graus. Os alunos fizeram a autocorreção de seus processos e assim perceberam em que circunstâncias incorriam em erros.

A aluna Cristine (Turma B) esclarece que essa forma de aprender matemática o auxiliou bastante.

"Aquela fórmula que tinha no caderno e que antes a professora passava, no GeoGebra você consegue enxergar mais, um além daquilo. Tudo pelo computador para mim é ótimo. (...) O Moodle era uma maneira de estudar a mais, porque Matemática para você entender você tem que praticar, e no Moodle era uma maneira de praticar também" (CRISTINE, EA).

A proposta da implementação do uso da Plataforma Moodle foi levada a cabo pelos três professores apesar das condições limitadas de acesso às salas de computação com disponibilidade de rede de Internet. Uma das razões pauta-se na questão das aulas de Matemática transcorrer em sua maioria em salas de aula onde os alunos necessitam apenas de cadernos, livros e materiais de escrita. Além disso, os professores também se depararam com um público de alunos que não tem o devido hábito de usar computador e vários alunos não possuem essa ferramenta e quando a tem não sabem ainda usá-la. Essa foi uma das considerações feita por Cristiano (Turma C), pois, segundo ele, a falta de condições adequadas para os alunos utilizarem um computador com acesso à Internet na sua escola dificultou o processo. Destaca-se que o professor dessa turma encontrou muita dificuldade para conciliar seu horário de aula com alguma sala de computadores disponível. Apesar dessa limitação, foi notária a diferença que fez aos alunos que puderam conhecer novas maneiras de adquiri conhecimentos matemáticos, conforme ressalta Eric: "o Moodle ele foi uma ferramenta, onde teve vídeos demonstrativos de um jeito mais fácil de aprender Matemática" (EA). Os alunos que tinham dificuldades ou mesmo quem não gostava de estudar essa disciplina notou que "foi um olhar diferente para a Matemática. (...) Saí daquela coisa de só utilizar o caderno" (SILVA, EA).

Infelizmente, nem todos os alunos tiveram as devidas condições de acesso ao ambiente virtual, dadas as circunstâncias da disponibilidade de computadores para toda a turma. Os alunos que mais participaram foram os que tinham computador com acesso à Internet em casa. Para Cristiano, "o que na verdade atrapalhou foi a falta da tecnologia. Como vai trabalhar com se não tem? Foi a falta de equipamentos (...) a dificuldade era ter espaço físico e computadores para trabalhar" (CRISTIANO, EA). O aluno Anderson (Turma C), em concordância com vários depoimentos de alunos das outras turmas, considera que "algumas pessoas também não tinham muita habilidade para estar mexendo" (EA). Além desse aspecto, observamos que as instituições ainda não estão devidamente equipadas para que os professores planejem suas aulas a partir do uso do computador com seus alunos. Ainda de acordo com Anderson, que não possui 
computador em casa, "o aspeto negativo foi o acesso ao computador, problemas era conseguir aulas e conseguir um espaço" (ANDERSON, EA). Por outro aspecto, Cristiano (Turma C) lembra que as poucas vezes que conseguiu utilizar os recursos tecnológicos na disciplina da Matemática o ajudou muito, especialmente "a questão de gráficos, conseguir visualizar de outra forma" (EA). O aluno Anderson (Turma C) lembra que no "geral foi bem interessante. Uma coisa diferente que a gente nunca tinha visto e auxilia no que vê na sala de aula" (EA).

\section{Considerações finais}

As diferentes atividades de aprendizagem que os alunos desenvolveram na Plataforma Moodle estimularam a sua curiosidade e criaram condições para uma aprendizagem mais autônoma. Em grande parte, a evolução na forma como os participantes deste estudo realizaram as atividades na Plataforma Moodle deveu-se à percepção de que podiam acessar a informação sobre conteúdos matemáticos para além do que lhes era apresentado pelo seu professor na sala de aula. Isso não ocorre quando é somente o professor o responsável pela transmissão dos assuntos matemáticos a serem estudados. Além de terem várias informações ao seu dispor, algumas por meio de vídeos, pesquisas entre outros, tiveram o e-mail e, em menor escala, o fórum como meio de interagir com os seus colegas e professor.

A utilização do computador no desenvolvimento de diferentes atividades na disciplina de Matemática desenvolve nos alunos novas habilidades e os faz participar mais ativamente das atividades de aprendizagem. Os intervenientes no estudo viram no computador uma ferramenta que os auxilia na sua aprendizagem, o que os estudos de Barcelos (2008) e Bastos Filho (2009) também evidenciam. A oportunidade que os alunos tiveram de trabalhar com o computador foi para muitos uma novidade. Inicialmente, os alunos mostraram-se ansiosos mediante a apresentação da proposta de integração do Moodle no ensino de Matemática, uma vez que até então, para eles, o responsável por apresentar os conhecimentos matemáticos era o professor. Numa primeira reação, parecia-Ihes ser impossível estudar e aprender conteúdos matemáticos utilizando recursos tecnológicos, especialmente através do computador. Essa atitude evidencia uma das características do público da EJA, pois, de certo modo, mostram-se resistentes ao desconhecido, neste caso unir o uso de computador e a aprendizagem de Matemática. Por outro lado, indicia que os professores dessa disciplina devem levar em consideração que os alunos da modalidade da Educação de Jovens e Adultos precisam que alguém lhes aponte e apresente algum diferencial.

Os resultados obtidos no estudo são inquietantes porque sinalizam o quanto esse público de alunos precisa de mais atenção, especialmente no que se refere à integração das TIC no processo de ensino e aprendizagem de Matemática. Os resultados mostram que os alunos do PROEJA foram receptivos ao dispositivo proposto, porém necessita-se de mais tempo para realizar 
esse tipo de trabalho com eles de modo que se soltem mais para escrever e enviar as suas mensagens e sistematizações sobre conteúdos matemáticos nos fóruns, promovendo discussões e reflexões com maior grau de profundidade.

Os aspectos que foram destacados pelos alunos, tais como estudar em silêncio de madrugada, rever e acessar os conhecimentos, perceber onde e por que erraram, estudar com mais autonomia, indicam alguns dos potenciais do uso das TIC. Destaca-se que isso representa um enorme ganho para os alunos do PROEJA porque a maioria deles compartilha o que aprende na escola com seus filhos, o que torna as discussões sobre a aprendizagem de conteúdos matemáticos mais significativos. Além disso, a partir deste estudo, os alunos se sentem mais confortáveis por saberem utilizar o computador para fazer pesquisas e complementar seus estudos, os quais são fatores que contribuíram para aproximá-los ainda mais de seus filhos.

Tais considerações levam a concluir que o dispositivo de ensino e aprendizagem da Matemática executado pelos três professores motivou os alunos e fortaleceu a aprendizagem de conteúdos matemáticos, fazendo-os superar as suas expectativas. Esse dispositivo proporcionou aos alunos deste estudo conhecimentos mais alargados resultantes da pesquisa de conteúdos matemáticos. Não chega oferecer diferentes meios para que os alunos busquem a informação, mas sim alargar o leque de possibilidades que estimule sua autonomia para que eles consigam produzir o conhecimento. Concluí-se que para pensar a educação na Sociedade da Informação requer que se considere a abrangência dos aspetos relativos às Tecnologias de Informação e Comunicação (TIC), principalmente pelo papel que a elas representam frente a construção de uma sociedade que prima pela inclusão e a justiça social (TAKAHASHI, 2000). Tal aspecto faz refletir que, para promover Sociedades do Conhecimento precisa-se, acima de tudo, que sejam ultrapassadas as desigualdades sociais. De acordo com o relatório mundial da UNESCO (2007), vislumbrar mudanças e pensar as Sociedades do Conhecimento como algo possível requer que os sujeitos inseridos nesta sociedade demonstrem algumas habilidades básicas. Como aponta esse relatório, todos os alunos devem ser capazes de, na sociedade atual, tirar partido da corrente de informação que nos envolve e a desenvolver capacidades de raciocínio cognitivo e crítico de modo a distinguir a informação 'útil' da 'inútil'.

O uso das TIC em diferentes atividades que os alunos realizam permite um maior envolvimento no processo de ensino e aprendizagem da Matemática do que sem esses recursos, pois podem extrapolar o tempo de sala de aula que é muito reduzido. O bom uso das TIC, em especial, o fórum e e-mail, visa propiciar espaços promissores de dinamização e complementação da componente presencial, pois podem desenrolar-se permanentemente para além dos momentos presenciais (VISEU e PONTE, 2009). As TIC, ao apoiarem o ensino presencial, favorecem o autoestudo, permitem a aprendizagem a distância bem como a extensão virtual do que se vivencia presencialmente na sala de aula. 


\section{Referências}

BIANCHETTI, L. Da chave de fenda ao laptop - tecnologia digital e novas qualificações: desafios à educação. Petrópolis: Vozes, 2001.

BOGDAN, R., \& BIKLEN, S. Investigação qualitativa em Educação: uma introdução à teoria e aos métodos. Porto: Porto Editora, 1994.

AUSUBEL, D. 0 uso de organizadores avançados no aprendizado e retenção do material verbal significativa. Journal of Educational Psychology, 51, 267-272, 1960.

AUSUBEL, D. Aquisição e retenção de conhecimentos: uma perspetiva cognitiva. Lisboa: Plátano, 2003.

BONILLA, M. H. Escola aprendente: para além da Sociedade da Informação. Rio de Janeiro: Quartet, 2005.

BORBA, M. C., \& PENTEADO, M. G. Informática e educação matemática. São Paulo: Autêntica Editora, 2007.

BRASIL. Decreto no 5·840, de 13 de julho de 2006. Diário Oficial [da] República Federativa do Brasil, Brasília, DF, 14 jul. 2006.

COAN, L. G. W. A aprendizagem de matemática de discentes do curso da Educação de Jovens e Adultos do IF-SC apoiada por um dispositivo de EaD. 2012. 467f. Tese (Doutorado em Educação Matemática). Universidade do Minho (UMINHO). Braga-PT.

DAVIS, P., \& HERSH, R. A experiência matemática. Lisboa: Gradiva, 1995.

DIAS, P. Processos de Aprendizagem Colaborativa nas Comunidades online. In A. A. S. DIAS, \& M. J. GOMES (Coords.), E-Learning para E-Formadores. Guimarães: TecMinho/Gabinete de Formação Contínua, Universidade do Minho, 2004.

ERICKSON, F. Qualitative methods in research on teaching. In M. WITTROCK (Ed.), Handbook of Research on Teaching (pp. 119-161). New York: Macmillan, 1986.

FLICK, U. Introdução à pesquisa qualitativa. Porto Alegre: Artmed, 2009.

KENSKI, V. M. Educação e tecnologias: o novo ritmo da informação. Campinas-SP: Papirus, 2008.

MASSON, G., \& MAINARDES, J. A ideologia da sociedade do conhecimento e suas implicações para a educação. Currículo sem Fronteiras, 11(2), 70-85, 2011.

MIRANDA, G. L. Limites e possibilidades das TIC na educação. Sísifo. Revista de Ciências da Educação, 3, 41-50, 2007.

PONTE, J. P. Tecnologias de informação e comunicação na educação e na formação de professores: Que desafios? Revista Ibero-Americana de Educação, 24, 63-90, 2000. 
PONTE, J. P., \& CANAVARRO, A. P. Matemática e novas tecnologias. Lisboa: Universidade Aberta, 1997.

TAKAHASHI, T. Sociedade da Informação no Brasil - Livro Verde. Brasília: Ministério da Ciência e da Tecnologia, 2000. Disponível em: <http://www.inst-informatica.pt/servicos/informacao-edocumentacao/biblioteca-digital/gestao-e- organizacao /BRASIL_livroverdeSI.pdf >. Acesso em: 27 de mar. 2011.

UNESCO (BINDE, Jerome (org.)). Rumo às Sociedades do Conhecimento. Relatório Mundial da UNESCO. Lisboa: Instituto PIAGET, 2007.

VISEU, F., \& PONTE, J. P. Desenvolvimento do conhecimento didático do futuro professor de Matemática com apoio das TIC. Revista Latinoamericana de Investigación en Matemática Educativa, 12(3), 383-413, 2009.

YIN, R. K. Estudo de caso: planejamento e métodos. Porto Alegre: Bookman, 2005.

LISANI GENI WACHHOLZ COAN - Doutora em Educação Matemática pela Universidade do Minho de Braga - Portugal. Aluna do Pós Doutorado no PPGECT da UFSC na área de aprendizagem matemática com uso novas semióticas (TIC) e formação de professores. Professora de Matemática do IFSC no Campus de Florianópolis/SC. E-mail: lisani@ifsc.edu.br

FLORIANO VISEU - Doutor em Educação, Especialidade Didática da Matemática, pela Universidade de Lisboa. Professor Auxiliar do Instituto de Educação, Universidade do Minho, na área de Educação Matemática. E-mail: fviseu@ie.uminho.pt 